\title{
Cardiocerebral resuscitation: advances in cardiac arrest resuscitation
}

\author{
Erwin Mulia, Bambang B. Siswanto
}

Department of Cardiology and Vascular Medicine, Faculty of Medicine, Universitas Indonesia/National Cardiovascular Center Harapan Kita, Jakarta, Indonesia

\begin{abstract}
Abstrak
Henti jantung masih merupakan penyebab kematian utama di dunia. Walau telah ada kemajuan dalam hal tatalaksana kegawatdaruratan kardiovaskular, angka ketahanan hidup mereka dengan henti jantung di luar rumah sakit tetap rendah. Pedoman resusitasi jantung paru dan kegawatdaruratan kardiovaskular meski telah diperbaharui namun pendekatan terhadap keadaan henti jantung di luar rumah sakit masih jauh dari optimal. Hal ini memberi peluang bagi resusitasi kardioserebral untuk menjadi alternatif resusitasi pada keadaan henti jantung di luar rumah sakit. Resusitasi kardioserebral layak menggantikan resusitasi jantung paru pada keadaan henti jantung di luar rumah sakit karena telah terbukti memperbaiki ketahanan hidup dan fungsi serebral pada pasien dengan henti jantung. (Med J Indones 2011; 20:306-9)
\end{abstract}

\begin{abstract}
Cardiac arrest remains a leading cause of death in the world. Although advances in emergency cardiac care has been achieved, the survival rate of those non hospitalized hospital cardiac arrest remains low. Update in guidelines for CPR and emergency cardiovascular, their approach to out of hospital cardiac arrest is far from optimal. This provides an opportunity to advocate cardiocerebral resuscitation as an alternative to traditional cardiopulmonary resuscitation for non hospitalized cardiac arrest. Because cardiocerebral resuscitation results in improved survival and cerebral function in patients with witnessed cardiac arrest and a shockable rhythm whom have greatest chance of survival, it should replace CPR especially for non hospitalized cardiac arrest. (Med J Indones 2011; 20:306-9)
\end{abstract}

Keywords: cardiocerebral resuscitation, cardiac arrest, cardiopulmonary resuscitation

Despite of the development of standards and guidelines for emergency cardiac care that included CPR (CardioPulmonary Resuscitation) and ACLS (Advanced Cardiac Life Support), the survival rate of victims of OHCA (Out of Hospital Cardiac Arrest) remains disappointingly low. Bystander CPR and rapid response times improve survival rates after OHCA. ${ }^{1-5}$ However, in this age of universal precautions, only 1 in 4 or 5 patients with OHCA currently receive bystander CPR. Survival to discharge in patients with witnessed OHCA and VF (Ventricular Fibrillation) improved by nearly $40 \%$ when they provide a single shock followed by immediate chest compressions rather than previously recommended stacked shocks. ${ }^{5}$ The initiations of bystander resuscitations, especially when begun within 1 minute of the arrest, markedly improve survival. ${ }^{6}$

\section{Rescue breathing}

"Rescue breathing" is a misnomer because this requirement decreases the survival chances of patients with witnessed cardiac arrest receiving bystander resuscitation. The requirement for mouth-to-mouth ventilations has several major drawbacks for patients with cardiac arrest. ${ }^{7}$ First, it decreases the number of individuals who receive prompt bystander resuscitation efforts. Most bystanders are not willing to initiate bystander rescue efforts because they are not willing to perform mouth-to-mouth ventilation. Second, "rescue breathing" results in long interruptions of chest compressions during cardiac arrest and long interruptions of chest compressions decrease neurologically normal survival. ${ }^{8}$ The 2005 CPR guidelines also changed their recommendation on compression to perfusion ratio $(30: 2)$, recognizing the importance of delivering more chest compressions with less interruptions. ${ }^{7}$ In laboratory model of clinically realistic $\mathrm{OHCA}$, normal neurologic survival was better with CCC (Continous Chest Compressions) than with 30:2 compressions to ventilations. ${ }^{9}$ The forward blood flow is so marginal during chest compressions for cardiac arrest, that any interruption of chest compressions decreases vital blood flow to the brain. Third, even if chest compressions are not interrupted, positive-pressure ventilation during cardiac arrest increases intrathoracic pressure then decreases venous return to the thorax and subsequent perfusion of the heart and the brain. ${ }^{10}$ This phenomenon is made worse when forceful ventilations are given while the chest is being compressed. ${ }^{11}$ Another concern is the amount of air that enters the stomach rather than the lungs during rescue breathing. Mouth-to-mouth ventilation can cause regurgitation in nearly $50 \%$ of patients. The pulmonary veins, left heart and entire arterial system are filled with oxygenated blood at the onset of VFinduced arrest. The important issue is to circulate such oxygenated blood to the tissues, particularly the brain and myocardium. The recommended ventilations further delay the onset of critical chest compressions. ${ }^{12}$ Finally, "rescue breathing" is not necessary in victims of witnessed cardiac arrest because they initially gasp and if chest compressions are started early and 
continued, many victims will continue to gasp and there by provide physiologic ventilation. ${ }^{13}$

\section{Cardiac arrest phase}

Early in cardiac arrest when adequate tissue oxygenation delivery is critically important, CCC provides this crucial oxygen delivery. ${ }^{14}$ Weisfeldt and Becker described 3-phase time-sensitive model of cardiac arrest due to VF which was the rationale of CCR (Cardio Cerebral Resuscitation) recommendation. ${ }^{15}$ The first phase, the electrical phase, lasts about 4 to $5 \mathrm{~min}$. The most important intervention during this phase is defibrillation. The second phase, the circulatory phase, which lasts approximately from minute 4 or 5 to minute 15. The generation of adequate cerebral and coronary perfusion pressures by chest compressions before and after defibrillation during this phase is critical to neurologically normal survival. Ironically, if an AED (Automatic External Defibrillator) is applied during this phase without pre-shock chest compressions, the subject is much less likely to survive and almost always results in asystole or pulseless electrical activity (PEA). The previous recommendation for a stacked-shock protocol resulted in prolonged interruption of chest compressions for rhythm analysis before and after shocks during the circulatory phase of cardiac arrest. ${ }^{16,17}$ Successful resuscitation of a patient with a pulseless rhythm usually requires pre-shock chest compressions and prompt effective resumption of chest compressions post-shock along with vasopressors. For these reasons, CCR recommends 200 chest compressions to provide myocardial perfusion prior to a single shock for VF in the circulatory phase and immediate application of another 200 chest compressions without prior assessment of the rhythm or pulse. ${ }^{18,19}$ Three pillars of CCR include CCC, CCR and post resuscitation care (hypothermia and early PCI).

\section{Cardiocerebral resuscitation}

Another reason that survival of OHCA has been so poor is that paramedics, who almost always arrive after the electrical phase of VF cardiac arrest, spend only one-half of the time doing chest compressions. ${ }^{16,20}$ Another major problem during resuscitation efforts is endotracheal intubation. Endotracheal intubation has adverse effects due to the relatively long interruptions of chest compressions during placement and adverse effects of positive-pressure ventilation and frequent hyperventilation. ${ }^{21}$ CCR accordingly discourages endotracheal intubation during the electrical and circulatory phases of cardiac arrest due to $\mathrm{VF}^{22}$

Another important aspects of CCR is that after the defibrillation shock, 200 additional chest compressions are provided before rhythm and pulse are analyzed. A defibrillation shock rarely produced a perfusion rhythm in prolonged VF. The VF almost always changes to either asystole or PEA. The key to successfully treating these postdefibrillation rhythms is urgent myocardial reperfusion. Chest compressions are of paramount importance after the defibrillation shock, especially in patients with PEA. Small pulsatile increases in aortic pressure post-shock (pseudopulseless electrical activity). Aortic pressures of 20/10 $\mathrm{mmHg}$ are common in such a period. If hemodynamic support is provided by immediate chest compressions, these pressures often increase to $40 / 20 \mathrm{mmHg}$ and will continue to increase. Withoutimmediate post-shock chestcompressions, the aortic pressure will decline and soon be truly asystolic. Therefore, CCR recommends for an additional 200 chest compressions immediately after the shock without a pause to assess the post-shock rhythm. ${ }^{18,19,22}$

A dramatic increase in neurologically intact survival were found with CCR. The mean survival to hospital discharge with intact neurologic function was $15 \%$ in the 3 years prior and $48 \%$ during the year when CCR was provided. ${ }^{22}$ In patients with witnessed cardiac arrest and shockable rhythm, there was dramatic improvement $(15 \%$ to $40 \%)$ in neurologic intact survival at hospital discharge compared with the pre-CCR era. ${ }^{23}$

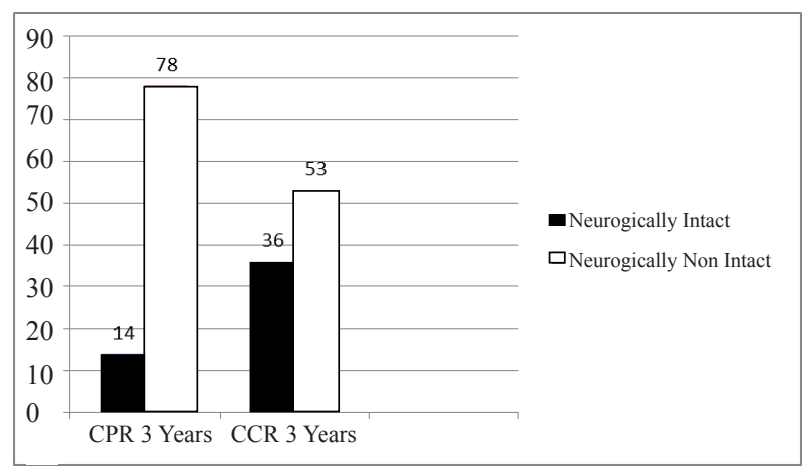

Figure 1. Neurologically normal survival of patients with witnessed OHCA and a shockable rhythm

\section{Therapeutic hypothermia and early PCI}

Sunde et al. performed an aggressive approach with post-resuscitation care patients. They emphasized therapeutic hypothermia to all who remained comatose post-resuscitation and performing early coronary angiography and percutaneous coronary intervention (PCI) in any patients with possible myocardial ischemia as a contributing factor to their cardiac arrests. They found a significant improvement in survival using this approach. During this interventional period, 77\% of all resuscitated victims had coronary angiography. The vast majority $(96 \%)$ of those undergoing cardiac catheterization had documented coronary disease and 
$82 \%$ of those had total occlusions of an epicardial coronary vessel. They revealed that reperfusion therapy was by far the most influential factor on survival. ${ }^{24}$

Finally, the neurologic status of long-term survivors during the experimental period of aggressive postresuscitation care was excellent, with more than $90 \%$ having no neurologic deficits and 9\% having mild deficits. These data suggest strongly that significant improvement in survival to discharge and even 1-year survival can be achieved with an aggressive and standardized approach to post-resuscitation care. Reperfusion therapy, either PCI or coronary artery bypass graft, had the most profound effect on outcome. Two large, randomized, prospective trials published in 2002 showed improved survival and neurologic function of survivors when therapeutic hypothermia $\left(32^{\circ} \mathrm{C}\right.$ to $34^{\circ} \mathrm{C}$ ) was used for comatose victims of OHCA. ${ }^{25,26}$

Quintero-Moran et al. found that 54\% patient with OHCA survived to hospital discharge with aggressive early cardiac catheterization and angioplasty strategy. ${ }^{27}$ Gorjup et al. reported survival to hospital discharge was achieved in $67 \%$ of 135 patients with STEMI and associated cardiac arrest. Among the patients who were comatose at the time of cardiac catheterization, survival was achieved in 51\% and the patients who were conscious after their cardiac arrests had a survival rate of $100 \%{ }^{28}$ Garot et al. reported on 186 patients suffering cardiac arrest as a complication of their myocardial infarctions (STEMI). Prior to cardiac catheterization, all of these patients were sedated and given neuromuscular blockage. Fifty-five percent survived to hospital discharge and among the survivors, $86 \%$ had normal neurologic function, $10 \%$ had mild disability and $4 \%$ were severely neurologically disabled. ${ }^{29}$

Knafelj et al. then reviewed the combination of these 2 important resuscitation therapies, hypothermia and early PCI. Their series contained 72 patients, all of whom were comatose post-resuscitation after cardiac arrest with signs of STEMI. The overall survival rate to hospital discharge was $61 \%$, but there was a significant difference between those who were cooled pre-PCI and those who were not. Of those who received both angioplasty and hypothermia, the hospital discharge survival rate was $75 \%$, with $73 \%$ of those survivors having good neurologic function. Among those who did not receive hypothermia, $44 \%$ were discharged from the hospital and only $16 \%$ had normal neurologic function. This is much better than what has been achieved without moderate hypothermia, early cardiac catheterization and PCI when indicated. For optimal results with CCR, aggressive post-resuscitation care that includes both of therapeutic hypothermia and emergent cardiac catheterization and PCI when appropriate must be included. Thus, this third component has been recently added to protocol of CCR. ${ }^{30}$

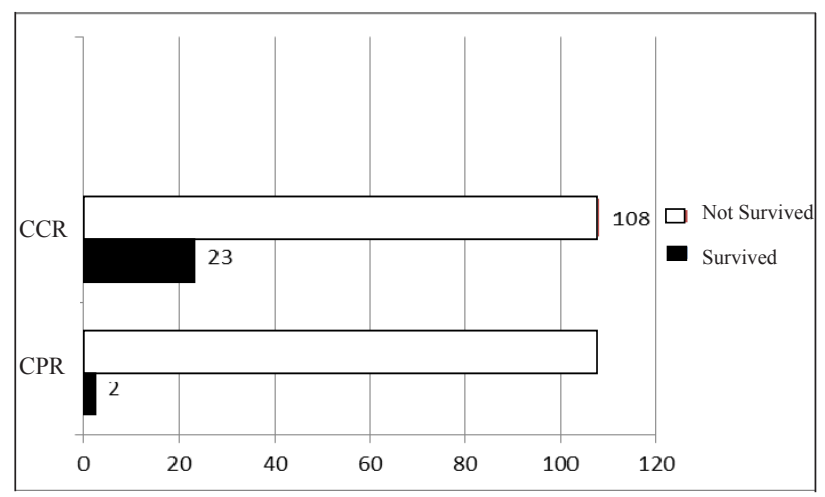

Figure 2. Survival to hospital discharge of patients with OHCA treated by 2 different emergency medical services protocols $(\text { OR } 8.6)^{14}$

Table 1. Comparison Between Cardiocerebral Resuscitation and AHA CPR

\begin{tabular}{lll}
\hline & Cardiocerebral Resuscitation 2003 & $\begin{array}{l}\text { AHA 2005 Guidelines and 2008 Advisory } \\
\text { Statement }\end{array}$ \\
\hline $\begin{array}{ll}\text { Chest Compression } \\
\text { Rescue Breathing }\end{array}$ & Continuous CC for bystanders & Bystander "hands-only" CPR \\
BLS & Decrease rescue breathing & Decrease CC interruptions \\
ACLS & No rescue breaths & $30: 2$ CCs to ventilations \\
& Passive oxygen insufflation or limited breaths/min & $8-10$ breaths/min \\
Post Cardiac Arrest Care & 200 CCs prior to shock & Optional 5 cycles of 30:2 prior to shock \\
& 200 CCs immediately after shock & 5 cycles of 30:2 immediately after shock \\
& Therapeutic hypothermia for all unconscious post-resuscitation & Therapeutic hypothermia for all unconscious \\
& & post-resuscitation from VFCA \\
\hline
\end{tabular}

ACLS = advanced cardiac life support; AHA = American Heart Association; BLS = basic life support; CC = chest compression; CPR = cardiopulmonary resuscitation; PCI = percutaneous coronary intervention; $\mathrm{VFCA}=$ ventricular fibrillation cardiac arrest] 
In conclusion, uninterrupted perfusion to the heart and brain by $\mathrm{CCC}$ prior to defibrillation during cardiac arrest is essential to neurologically normal survival. CCC CPR by bystanders as a solution to this critical issue because eliminating mouth-to-mouth "rescue breathing" will go a long way toward increasing the incidence of bystander resuscitation efforts. These changes resulted in dramatic improvement in survival of patients most likely to survive: those with witnessed cardiac arrest and shockable rhythm. More aggressive post-resuscitation care, including hypothermia and emergent cardiac catheterization and PCI, are required to save more victims of sudden cardiac arrest.

\section{REFERENCES}

1. Iwami T, Kawamura T, Hiraide A, Berg RA, Hayashi Y, Nishiuchi $T$, et al. Effectiveness of bystander-initiated cardiac-only resuscitation for patients with non hospitalized cardiac arrest. Circulation 2007;116:2900-7.

2. Bohm K, Rosenqvist M, Herlitz J, Hollenberg J, Svensson L. Survival is similar after standard treatment and chest compression only in non hospitalized bystander cardiopulmonary resuscitation. Circulation 2007;116:290812.

3. Rea TD, Helbock M, Perry S, Garcia M, Cloyd D, Becker $\mathrm{L}$, et al. Increasing use of cardiopulmonary resuscitation during non hospitalized ventricular fibrillation arrest: survival implications of guideline changes. Circulation 2006;114:2760-5.

4. Steen S, Liao Q, Pierre L, Paskevicius A, Sjöberg T. The critical importance of minimal delay between chest compressions and subsequent defibrillation: a haemodynamic explanation. Resuscitation 2003;58:249-58.

5. 2005AmericanHeartAssociationguidelinesforcardiopulmonary resuscitation and emergency cardiovascular care: part 2: adult basic life support. Circulation 2005;112 Suppl I:III5-16.

6. Kern KB, Hilwig RW, Berg RA, Sanders AB, Ewy GA. Importance of continuous chest compressions during cardiopulmonary resuscitation: improved outcome during a simulated single lay-rescuer scenario. Circulation 2002;105:645-9.

7. Ewy GA, Zuercher M, Hilwig RW, Sanders AB, Berg $\mathrm{RA}$, Otto $\mathrm{CW}$, et al. Improved neurological outcome with continuous chest compressions compared with 30:2 compressions-to-ventilations cardiopulmonary resuscitation in a realistic swine model of non hospitalized cardiac arrest. Circulation 2007;116:2525-30.

8. Aufderheide TP, Sigurdsson G, Pirrallo RG, Yannopoulos D, McKnite S, von Briesen C, et al. Hyperventilationinduced hypotension during cardiopulmonary resuscitation. Circulation 2004;109:1960-5.

9. Aufderheide TP, Lurie KG. Death by hyperventilation: a commonandlife-threateningproblemduring cardiopulmonary resuscitation. Crit Care Med 2004;32:345-51.
10. Meursing BT, Wulterkens DW, van Kesteren RG. The $\mathrm{ABC}$ of resuscitation and the Dutch (re)treat. Resuscitation 2005;64:279-86.

11. Bobrow BJ, Clark LL, Ewy GA, Chikani V, Sanders AB, Berg RA, et al. Minimally interrupted cardiac resuscitation by emergency medical services providers for non hospitalized cardiac arrest. JAMA 2008;229:1158-65.

12. Weisfeldt M, Becker L. Resuscitation after cardiac arrest: a 3-phase time-sensitive model. JAMA 2002;288:3035-8.

13. Valenzuela T, Kern K, Clark L, Berg RA, Berg MD, Berg DD, et al. Interruptions of chest compressions during emergency medical systems resuscitations. Circulation 2005;112:1259-65.

14. Wik L, Hansen TB, Fylling F, Steen T, Vaagenes P, Auestad $\mathrm{BH}$, et al. Delaying defibrillation to give basic cardiopulmonary resuscitation to patients with non hospitalized ventricular fibrillation: a randomized trial. JAMA 2003;289:1389-95.

15. EwyG.Cardiocerebralresuscitation:thenewcardiopulmonary resuscitation. Circulation 2005;111:2134-42.

16. Wik L, Kramer-Johansen J, Myklebust H, Sorebo H, Svensson L, Fellows B, et al. Quality of cardiopulmonary resuscitation during non hospitalized cardiac arrest. JAMA 2005;293:299-304.

17. Kellum MJ, Kennedy KW, Ewy GA. Cardiocerebral resuscitation improves survival of patients with non hospitalized cardiac arrest. Am J Med 2006;119:335-40.

18. Kellum MJ, Kennedy KW, Barney R, Keilhauer FA, Bellino M, Zuercher M, et al. Cardiocerebral resuscitation improves neurologically intact survival of patients with non hospitalized cardiac arrest. Ann Emerg Med 2008;52:24452.

19. Sunde K, Pytte M, Jacobsen D, Mangschau A, Jensen LP, Smedsrud C, et al. Implementation of a standardised treatment protocol for post resuscitation care after non hospitalized cardiac arrest. Resuscitation 2007;73:29-39.

20. Hypothermia after Cardiac Arrest Study Group. Mild hypothermia to improve the neurologic outcome after cardiac arrest. N Engl J Med 2002;346:549-56.

21. Bernard SA, Gray TW, Buist MD, Jones BM, Silvester W, Gutteridge G, et al. Treatment of comatose survivors of non hospitalized cardiac arrest with induced hypothermia. N Engl J Med 2002;346:557-63.

22. Quintero-Moran B, Moreno R, Villarreal S, Perez-Vizcayno MJ, Hernandez R, Conde C, et al. Percutaneous coronary intervention for cardiac arrest secondary to ST-elevation acute myocardial infarction. Influence of immediate paramedical/ medical assistance on clinical outcome. J Invasive Cardiol 2006;18:269-72.

23. Gorjup V, Radsel P, Kocjancic ST, Erzen D, Noc M. Acute STelevationmyocardial infarction aftersuccessful cardiopulmonary resuscitation. Resuscitation 2007;72:379-85.

24. Garot P, Lefevre T, Eltchaninoff H, Morice MC, Tamion F, Abry B, et al. Six-month outcome of emergency percutaneous coronary intervention in resuscitated patients after cardiac arrest complicating ST-elevation myocardial infarction. Circulation 2007;115:1354-62.

25. Knafelj R, Radsel P, Ploj T, Noc M. Primary percutaneous coronary intervention and mild induced hypothermia in comatose survivors of ventricular fibrillation with ST-elevation acute myocardial infarction. Resuscitation 2007;74:227-34. 